\title{
The Relationship between Serum Oxalic Acid, Central Hemodynamic Parameters and Colonization by Oxalobacter formigenes in Hemodialysis Patients
}

\author{
Baris Gulhan $^{a}$ Kultigin Turkmen ${ }^{c}$ Merve Aydin ${ }^{a}$ Murat Gunay ${ }^{b}$ \\ Aytekin Cıkman $^{a}$ Murat Kara ${ }^{a}$
}

Departments of a Microbiology and biochemistry, School of Medicine, Erzincan University, Erzincan, and ' Division of Nephrology, Department of Internal Medicine, Meram School of Medicine, Konya Necmettin Erbakan University, Konya, Turkey

\author{
Key Words \\ Oxalobacter formigenes · Oxalic acid · Pulse wave velocity · Central aortic blood pressures . \\ Colo-reno-cardiac axis
}

\begin{abstract}
Background/Objective: Elevated pulse wave velocity (PWV) and central aortic blood pressures are independent predictors of increased cardiovascular morbidity and mortality in hemodialysis (HD) patients. Oxalic acid is a uremic retention molecule that is extensively studied in the pathogenesis of calcium oxalate stones. Oxalobacter formigenes, a member of the colon microbiota, has important roles in oxalate homeostasis. Data regarding the colonization by and the exact role of $O$. formigenes in the pathogenesis of oxalic acid metabolism in HD patients are scant. Hence, we aimed to determine the relationship between fecal $O$. formigenes colonization, serum oxalic acid and hemodynamic parameters in HD patients with regard to the colo-reno-cardiac axis. Methods: Fifty HD patients were enrolled in this study. PWV and central aortic systolic (cASBP) and diastolic blood pressures (CADBP) were measured with a Mobil-O-Graph (I.E.M. GmbH, Stolberg, Germany). Serum oxalic acid levels were assessed by ELISA, and fecal $O$. formigenes DNA levels were isolated and measured by real-time PCR. Results: Isolation of fecal $O$. formigenes was found in only $2 \mathrm{HD}$ patients. One of them had 113,609 copies $/ \mathrm{ml}$, the other one had 1,056 copies $/ \mathrm{ml}$. Serum oxalic acid levels were found to be positively correlated with PWV $(r=0.29, p=0.03)$, CASBP $(r=0.33, p=0.001)$ and $\operatorname{cADBP}$
\end{abstract}

B. Gulhan and K. Turkmen contributed equally to this work. 
Gulhan et al.: The Relationship between Serum Oxalic Acid, Central Hemodynamic

$(r=0.42, p=0.002)$ and negatively correlated with $L D L(r=-0.30, p=0.03)$. In multivariate linear regression analysis, PWV was independently predicted by oxalic acid, glucose and triglyceride. Conclusions: This is the first study that demonstrates the absence of $O$. formigenes as well as a relation between serum oxalic acid and CASBP, CADBP and PWV in HD patients. Replacement of $O$. formigenes with pre- and probiotics might decrease serum oxalic acid levels and improve cardiovascular outcomes in HD patients.

(c) 2015 S. Karger AG, Basel

\section{Introduction}

Cardiovascular diseases (CVDs) are still the leading cause of morbidity and mortality in chronic kidney disease (CKD) patients receiving hemodialysis (HD) [1]. Many traditional and nontraditional novel risk factors including inflammation, endothelial dysfunction, vascular calcification and oxidative stress have been identified; however, the death rates from CVDs remain fivefold higher among HD patients than in the general population [2]. In this regard, Evenepoel et al. [3] suggested alternative uremic toxins originating from the degradation products of gut microbiota to explain this heightened morbidity and mortality from CVDs in CKD patients. Among them, $p$-cresol sulfate and indoxyl sulfate were the most commonly studied uremic retention molecules (URMs) [4, 5]. Oxalic acid is another exogenous URM that is extensively studied in the pathogenesis of calcium oxalate stone formation in patients with idiopathic primary hyperoxaluria [6, 7]. Mounting evidence demonstrates that colonic microbiota including Oxalobacter formigenes had important roles in oxalate homeostasis, and colonization by these bacteria was found to be closely associated with a reduced prevalence of oxalate stones in the general population [8,9]. However, in the literature, data regarding the colonization by and the exact role of $O$. formigenes in the pathogenesis of oxalic acid metabolism in HD patients are scant.

We hypothesized that degradation of oxalic acid might be insufficient in HD patients because of undercolonization of their colon by 0 . formigenes [10]. To test this hypothesis, we aimed to determine the quantity of $O$. formigenes in the feces of HD patients as well as the serum oxalic acid levels. We suggest that increased oxalic acid levels might be associated with endothelial dysfunction and aortic stiffness, both of which are commonly seen in HD patients [11]. Measuring pulse wave velocity (PWV) is accepted as a reliable means of determining aortic stiffness [12]. Hence, we also sought to investigate the relationship between pulse wave analysis, central aortic blood pressure measurements and serum oxalic acid and other parameters in this population.

\section{Subjects and Methods}

\section{Study Population}

The study protocol was approved by the Medical Ethics Committee of Erzincan University (Mengucek Gazi Training and Research Hospital, Erzincan, Turkey). Written informed consent was obtained from all the subjects included in this study. This was a cross-sectional trial involving 50 ESRD patients (23 women, 27 men; mean age: $62 \pm 14.9$ years) who had received HD for $\geq 6$ months in the dialysis unit of Erzincan University between May and July 2014.

Patients aged 18-70 years willing to participate in the assessment of PWV were screened. A review of their medical records (including information on age, gender, weight, duration of renal replacement treatment, medications and primary disease of ESRD) was undertaken. The exclusion criteria were: (1) primary hyperoxaluria; (2) active infection; (3) antibiotic usage in the previous 3 months; (4) utilization of calcium- and non-calcium-containing phosphate binders; (5) bisacodyl usage, and (6) use of pyridoxine and ascorbic acid replacement. Ninety-two HD patients were evaluated, and 42 patients were excluded from the study. Of these 


\section{CardioRenal Medicine}

Fig. 1. Flow chart showing HD patient screening and inclusion.

\begin{tabular}{l|l}
\hline Cardiorenal Med 2015;5:164-174 \\
\hline DOI: 10.1159/000381219 & $\begin{array}{l}\text { @ 2015 S. Karger AG, Basel } \\
\text { www.karger.com/crm }\end{array}$ \\
\hline
\end{tabular}

Gulhan et al.: The Relationship between Serum Oxalic Acid, Central Hemodynamic Parameters and Colonization by Oxalobacter formigenes in Hemodialysis Patients

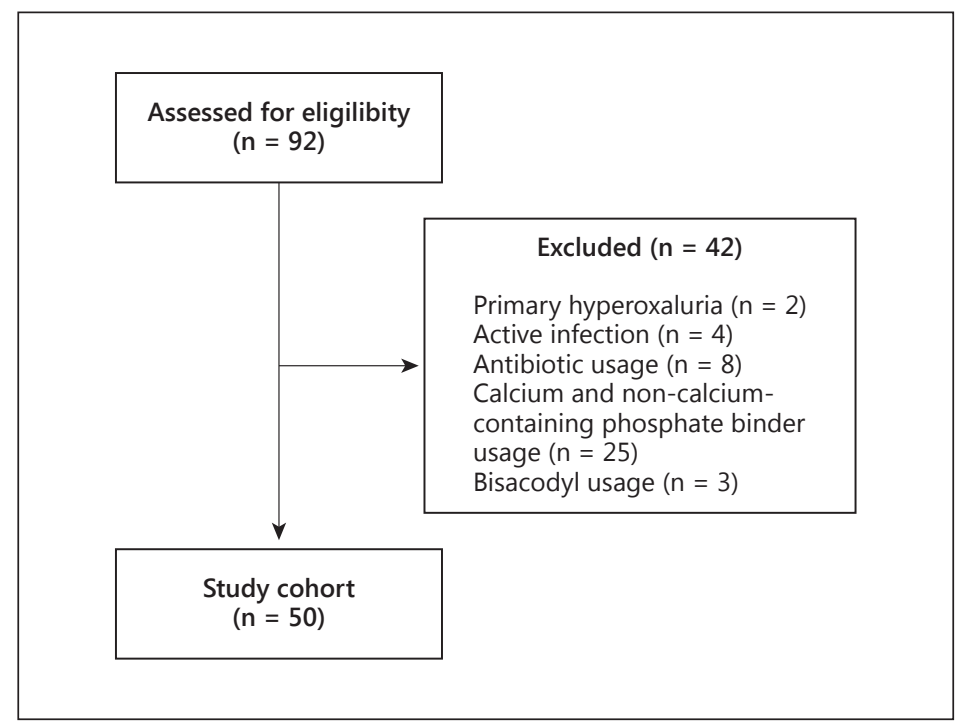

42 patients, 2 patients had primary hyperoxaluria, 4 had active infections, 8 used antibiotics, 25 used calciumand non-calcium-containing phosphate binders, and 3 used bisacodyl for chronic constipation. None of our patients used pyridoxine and ascorbic acid replacement. The remaining 50 ESRD patients fulfilled the above criteria and were enrolled in the study. The flow chart showing the screening and enrolment of the HD patients is depicted in figure 1.

The HD patients were receiving a thrice-weekly dialysis for a 4-hour period with a standard bicarbonatecontaining dialysate bath using a biocompatible HD membrane (Polysulfone, FX-80 series; Fresenius, Bad Homburg, Germany). The dialysate flow rate was $500 \mathrm{ml} / \mathrm{min}$, and the blood flow rates were 250-300 ml/ min. Systolic (SBP) and diastolic blood pressures (DBP) of the patients and healthy subjects were measured in the upright sitting position after 5 min of rest using an Erka sphygmomanometer (PMS Instruments Ltd., Maidenhead, UK) with an appropriate cuff size. Two readings were recorded for each individual. The mean value of the 2 readings was defined as the blood pressure. Patients with an SBP and a DBP of 140 and $90 \mathrm{~mm}$ $\mathrm{Hg}$, respectively, or those who were already on antihypertensive treatment, were assumed to be hypertensive. Twenty-two patients were taking antihypertensive drugs; 8 of them were on angiotensin-converting enzyme inhibitors, 4 were receiving angiotensin II receptor blockers, and 10 were receiving a calcium channel blocker.

\section{Biochemical Analyses}

Venous blood samples for biochemical analyses were drawn before the midweek session in patients receiving HD. All biochemical analyses, including those of total cholesterol, LDL cholesterol, HDL cholesterol and plasma triglyceride concentrations, were undertaken using an oxidase-based technique of the Roche/ Hitachi Modular System (Roche Diagnostics, Mannheim, Germany) in the Central Biochemistry Laboratory of the Mengucek Gazi Training and Research Hospital of Erzincan University.

\section{Measurement of Serum Oxalic Acid Levels}

Serum oxalic acid was measured with a commercially available kit (SunRed Biological Technology; serial No. 201-12-2153) using the human oxalic acid ELISA method. The intra-assay coefficient of variation was $<10 \%$, and the interassay coefficient of variation was $<12 \%$, as provided by the manufacturer.

\section{Determination of O. formigenes in Feces}

Fresh fecal samples were collected from all HD patients and stored at $-20^{\circ} \mathrm{C}$ before DNA isolation was performed. DNA was extracted from the samples using a QIAamp DNA Stool Mini Kit (Qiagen, Valencia, Calif., USA) according to the manufacturer's instructions.

After DNA isolation, quantification of 0 . formigenes was performed by real-time PCR with the Advanced Kit manufactured by Primer Design Ltd. (Rownhams, UK) and was analyzed with Rotor-Gene Q (Qiagen, Hilden, Germany). Reactions were carried out in accordance with the manufacturer's instructions. To prepare a standard curve, serial dilutions of positive controls were performed. 


\section{CardioRenal Medicine}

Table 1. Demographic, clinical and central hemodynamic parameters of the HD patients $(n=50)$

\begin{tabular}{l|l}
\hline \multicolumn{2}{l}{ Cardiorenal Med 2015;5:164-174 } \\
\hline DOI: 10.1159/000381219 & $\begin{array}{l}\text { @ 2015 S. Karger AG, Basel } \\
\text { www.karger.com/crm }\end{array}$ \\
\hline
\end{tabular}

Gulhan et al.: The Relationship between Serum Oxalic Acid, Central Hemodynamic Parameters and Colonization by Oxalobacter formigenes in Hemodialysis Patients

\begin{tabular}{lc}
\hline Age, years & $62.0 \pm 14.9$ \\
Female/male, $\mathrm{n}$ & $23 / 27$ \\
BMI & $26.5 \pm 5.6$ \\
Disease duration, months & $62 \pm 54$ \\
SBP, mm Hg & $139 \pm 36$ \\
DBP, mm Hg & $82 \pm 21$ \\
cASBP, mm Hg & $126 \pm 32$ \\
cADBP, mm Hg & $84 \pm 22$ \\
Mean blood pressure, mm Hg & $108 \pm 27$ \\
Pulse pressure, mm Hg & $56 \pm 21$ \\
PWV, m/s & $9.4 \pm 2.5$
\end{tabular}

Data are presented as means \pm SD unless specified otherwise. $\mathrm{BMI}=$ Body mass index.

Definition of Platelet-to-Lymphocyte and Neutrophil-to-Lymphocyte Ratios

Complete blood counts with automated differential counts, which included total white blood cells, neutrophils and lymphocytes, were obtained at the time of admission. Neutrophil-to-lymphocyte (NLR) and platelet-to-lymphocyte ratios (PLR) were calculated as the ratio of neutrophils and platelets to lymphocytes, both obtained from the same automated blood sample at admission to the study.

\section{PWV and Central Aortic Blood Pressure Measurements}

Vascular studies were performed in a quiet, temperature-controlled room with the subjects resting in a supine position. Central aortic systolic (CASBP) and diastolic blood pressures (cADBP) were measured in duplicate using a semiautomated, noninvasive oscillometric sphygmomanometer following a 10-min rest period. PWV was measured with a Mobil-O-Graph 24-h PWA Monitor, an automatic oscillometric device (I.E.M. GmbH, Stolberg, Germany) in accordance with the manufacturer's recommendations.

\section{Statistical Analyses}

All statistical analyses were performed using SPSS 15.0 (SPSS Inc., Chicago, Ill., USA). Continuous variables were tested for normal distribution by the Kolmogorov-Smirnov test. Continuous variables with normal distribution are presented as means \pm SD. Median values are used where a normal distribution was absent. Statistical analysis for the parametric variables was performed using Student's t test between two groups. The Mann-Whitney U test was used to compare nonparametric variables between two groups. Qualitative variables are given as percentages, and the correlation between categorical variables was investigated using the $\chi^{2}$ test. Linear associations between continuous variables were assessed using the Spearman correlation test. Multivariate linear regression analyses were undertaken to determine independent associations between PWV and other variables. Serum glucose, urea, albumin, triglyceride, oxalic acid and NLR were entered into the regression model as independent variables, and PWV was entered as a dependent variable. The backward elimination method was preferred in the stepwise regression analysis, and $\mathrm{p}>0.1$ was used as a criterion for elimination in this model. At the end of the fourth step, three variables (oxalic acid, triglyceride and glucose) remained statistically significant in the model. $\mathrm{p}<0.05$ was considered significant for all tests.

\section{Results}

The baseline characteristics as well as laboratory parameters of the 50 HD patients are presented in tables 1 and 2. The etiologies of ESRD were diabetic nephropathy $(n=17)$, hypertensive nephropathy $(n=15)$, chronic glomerulonephritis $(n=6)$, polycystic kidney disease $(n=2)$ and unknown $(n=10)$.

Isolation of fecal 0 . formigenes was found in only 2 HD patients. One of them had 113,609 copies $/ \mathrm{ml}$, the other one had 1,056 copies $/ \mathrm{ml}$. 


\section{CardioRenal Medicine}

Table 2. Laboratory parameters of the HD patients $(n=50)$

\begin{tabular}{lc}
\hline Cardiorenal Med 2015;5:164-174 \\
\hline DOI: 10.1159/000381219 & @ 2015 S. Karger AG, Basel \\
www.karger.com/crm
\end{tabular}

Data are presented as means $\pm \mathrm{SD}$. CRP $=$ C-reactive protein; $\mathrm{PTH}=$ parathyroid hormone.

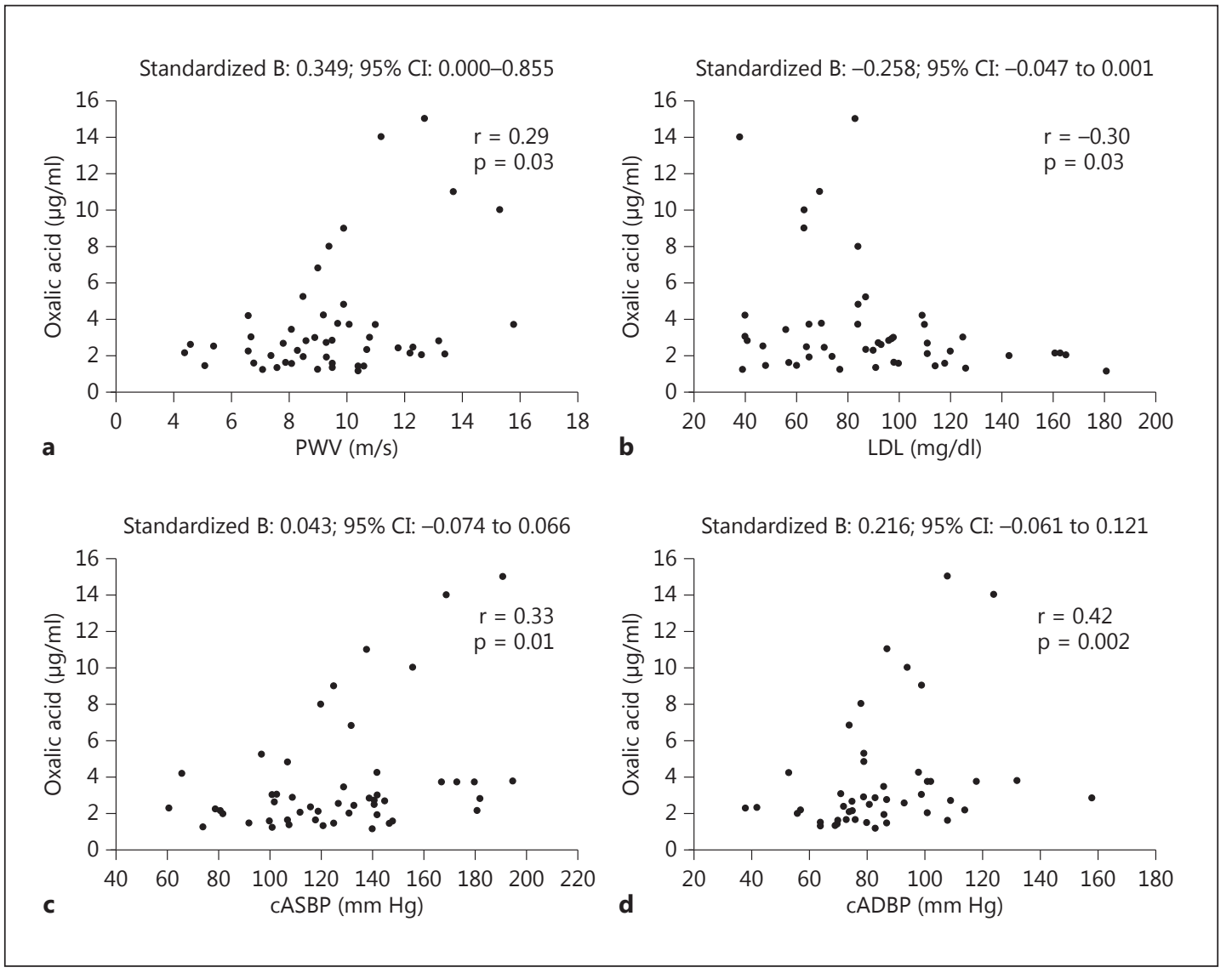

Fig. 2. Correlation analysis between serum oxalic acid and PWV (a), LDL in HD patients (b), cASBP (c) and cADBP (d). 


\section{CardioRenal Medicine}

Table 3. Variables of PWV in the HD patients

\begin{tabular}{l}
\hline Cardiorenal Med 2015;5:164-174 \\
\begin{tabular}{l|l}
\hline DOI: $10.1159 / 000381219$ & $\begin{array}{l}\text { (c) 2015 S. Karger AG, Basel } \\
\text { www.karger.com/crm }\end{array}$ \\
\hline Gulhan et al.: The Relationship between Serum Oxalic Acid, Central Hemodynamic
\end{tabular}
\end{tabular}

Gulhan et al.: The Relationship between Serum Oxalic Acid, Central Hemodynamic
Parameters and Colonization by Oxalobacter formigenes in Hemodialysis Patients

\begin{tabular}{lrrlr}
\hline Parameters & $\begin{array}{l}\text { Standardized } \\
\beta\end{array}$ & $\mathrm{t}$ & \multicolumn{1}{l}{$\begin{array}{l}\text { v } \\
\text { value }\end{array}$} \\
\hline Step 1 & & & & \\
Oxalic acid, $\mu \mathrm{g} / \mathrm{ml}$ & 0.261 & 2.00 & 0.05 & -0.002 to 0.428 \\
Urea, $\mathrm{mg} / \mathrm{dl}$ & 0.175 & 1.28 & 0.20 & -0.008 to 0.036 \\
Triglyceride, mg/dl & -0.203 & -1.51 & 0.13 & -0.011 to 0.002 \\
Albumin, g/dl & -0.044 & -0.29 & 0.77 & -2.025 to 1.515 \\
Glucose, $\mathrm{mg} / \mathrm{dl}$ & 0.334 & 2.56 & 0.01 & -0.083 to 0.338 \\
NLR & 0.160 & 1.22 & 0.22 & -0.193 to 0.167 \\
\hline Step 4 & & & & \\
Oxalic acid, $\mu \mathrm{g} / \mathrm{ml}$ & 0.347 & 2.878 & 0.006 & $0.086-0.481$ \\
Triglyceride, $\mathrm{mg} / \mathrm{dl}$ & -0.247 & -2.053 & 0.046 & $-0.011-0.000$ \\
Glucose, $\mathrm{mg} / \mathrm{dl}$ & 0.387 & 3.259 & 0.002 & $0.007-0.028$ \\
\hline
\end{tabular}

Step 1: $r^{2}=0.41 ;$ adjusted $r^{2}=0.33 ; p=0.001$. Step $4: r^{2}=0.36$; adjusted $\mathrm{r}^{2}=0.32 ; \mathrm{p}<0.0001$.

Linear Correlations

In the bivariate correlation analysis, serum oxalic acid levels were found to be positively correlated with PWV $(r=0.29, p=0.03)$, SBP $(r=0.29, p=0.03)$, DBP $(r=0.42, p=0.002)$, $\operatorname{cASBP}(r=0.33, p=0.001)$, cADBP $(r=0.42, p=0.002)$, mean blood pressure $(r=0.34, p=$ $0.01)$ and urea $(r=0.33, p=0.01)$ and negatively correlated with LDL $(r=-0.30, p=0.03)$ (fig. 2).

PWV was positively correlated with advanced age $(\mathrm{r}=0.83, \mathrm{p}<0.0001)$, SBP $(\mathrm{r}=0.62$, $\mathrm{p}<0.0001)$, DBP $(\mathrm{r}=0.43, \mathrm{p}=0.002)$, cASBP $(\mathrm{r}=0.75, \mathrm{p}<0.0001)$, $\operatorname{cADBP}(\mathrm{r}=0.45, \mathrm{p}=0.001)$, mean blood pressure $(r=0.56, p<0.0001)$, serum glucose $(r=0.55, p<0.0001)$, urea $(r=$ $0.35, \mathrm{p}=0.01)$, NLR $(\mathrm{r}=0.47, \mathrm{p}=0.01)$ and PLR $(\mathrm{r}=0.28, \mathrm{p}=0.04)$ and negatively correlated with albumin $(r=-0.35, p=0.01)$ and triglyceride levels $(r=-0.31, p=0.02)$.

The independence of multiple correlations was analyzed by multivariate linear regression analyses. Since advanced age as well as SBP and DBP are closely associated with PWV in the general and the HD population, we included glucose, urea, albumin, triglyceride, oxalic acid and NLR in the original model to define the other independent parameters of PWV in HD patients. In all subjects, PWV was independently predicted by oxalic acid, glucose and triglyceride (table 3).

\section{Discussion}

The present study is the first to evaluate the presence/absence of fecal $O$. formigenes colonization and the relationship between serum oxalic acid, PWV and central hemodynamic parameters in HD patients. There are three main findings. First, we could not isolate fecal $O$. formigenes in most of the HD patients. Second, serum oxalic acid levels are found to be positively correlated with PWV, cASBP, cADBP and urea and negatively correlated with LDL. Third, PWV was independently predicted by serum oxalic acid, glucose and triglyceride.

Previous studies have demonstrated that both quantitative and qualitative changes regarding the colonic microbiota are observed in HD patients. Anaerobic bacteria including Bifidobacterium, Lactobacillus and Prevotella are decreased, and the numbers of Clostridium perfringens, aerobic enterococci and enterobacteria are increased in HD patients when 
Gulhan et al.: The Relationship between Serum Oxalic Acid, Central Hemodynamic Parameters and Colonization by Oxalobacter formigenes in Hemodialysis Patients

compared with healthy subjects [13]. The main reasons for these changes include chronic constipation, delayed colonic transit times, decreased consumption of dietary fiber and impairment of protein assimilation in the small intestine secondary to the uremic milieu in HD patients [14-17]. As a consequence of these changes, the steady state of the colonic microbiota is impaired and the absorption of potentially toxic protein fermentation metabolites such as phenols, indoles, thiols, amines and oxalic acid is increased in these patients. Among others, oxalic acid is one of the least studied uremic toxins in the genesis of endothelial dysfunction and CVDs in HD patients.

O. formigenes, a Gram-negative anaerobic bacterium, both degrades and secretes ingested oxalate via feces in normal circumstances [18]. The latter function is found to be putatively mediated by anion transporter 1 [19]. In this regard, the role of $O$. formigenes therapy was extensively studied in an animal model of primary hyperoxaluria and in patients with primary hyperoxaluria and calcium oxalate kidney stones [20, 21]. In CKD patients, Hatch et al. [22] found that oxalate secretion is increased via colon-related adaptive mechanisms.

Humans lack the enzymes needed to directly metabolize oxalate; hence, this should be managed using alternative pathways. Although there are huge individual differences, oxalic acid-degrading bacteria are present in the endogenous microbiota of the human intestine. Recently, Mogna et al. [23] demonstrated the potential therapeutic application of some probiotics, mainly Lactobacillus and Bifidobacterium species, in order to reduce hyperoxaluria in vitro using reversed-phase high-performance liquid chromatography. In this study, researchers tested the oxalate-degrading activity of 13 lactobacilli and 5 bifidobacteria, and 0 . formigenes was used as the positive reference to validate the capability of highperformance liquid chromatography to assess oxalate degradation. They found that Lactobacillus strains were more efficient than bifidobacteria in degrading oxalates. According to the results of this study, the authors concluded that the administration of selected oxalatedegrading probiotics could be an alternative and innovative approach to reducing the intestinal absorption of oxalate and the resulting urinary excretion in the normal population.

Against this background, in the present study, we first of all assessed the colonization of the feces of the HD patients by 0 . formigenes. Isolation of fecal $O$. formigenes colonization was found in only $2 \mathrm{HD}$ patients. Although it appears that a large proportion of normal individuals are colonized, there is substantial variation in the reported prevalence in adults. The estimated prevalence of 0 . formigenes colonization ranged from 40 to $77 \%$ in healthy adult subjects from various countries [8]. Prokopovich et al. [24] also showed that the concentrations of $O$. formigenes ranged from below the limit of detection at $5 \times 10^{3}$ to 1.04 $\times 10^{9}$ cells per gram of stool in the normal population. The logical reasons for this finding include a lowered consumption of pre- and probiotics as well as a diversified colonic flora secondary to the uremic milieu in the colons of HD patients. None of our patients had used antibiotics 3 months prior to sample collection. When we checked the dietary characteristics of the $2 \mathrm{HD}$ patients who had enough $O$. formigenes colonization, we realized that they regularly consumed 2 bowls of yogurt and/or 1 glass of buttermilk every day. Yogurt, as a probiotic, contains Lactobacillus acidophilus, L. casei and Bifidobacterium. As we have mentioned above, the balance between anaerobic and aerobic microorganisms is impaired in HD patients. Effective probiotics are required to have some impact such as reducing pathogenic adherence, producing bacteriocins antagonistic to pathogen growth or forming a normal, balanced gastrointestinal flora $[25,26]$. As an example, the antimicrobial probiotic effects of kefir are noteworthy. Kefir is an acidic, viscous, slightly alcoholic, fermented dairy beverage which is produced by the actions of bacteria and yeast embedded in a resilient, insoluble protein/polysaccharide matrix known as a 'kefir grain' $[27,28]$. The organisms in 


\section{CardioRenal Medicine}

\begin{tabular}{l|l}
\hline Cardiorenal Med 2015;5:164-174 \\
\hline DOI: 10.1159/000381219 & $\begin{array}{l}\text { (c) 2015 S. Karger AG, Basel } \\
\text { www.karger.com/crm }\end{array}$ \\
\hline
\end{tabular}

Gulhan et al.: The Relationship between Serum Oxalic Acid, Central Hemodynamic Parameters and Colonization by Oxalobacter formigenes in Hemodialysis Patients

kefir produce many known antimicrobials, including lactic acid, acetic acid, carbon dioxide, hydrogen peroxide, ethanol and diacetyl, as well as antimicrobial peptides such as bacteriocins [27]. In addition, kefir may prove useful in the probiotic area as a delivery system for viable health-promoting organisms to the gut [29]. In this regard, probiotics might rearrange the colonic flora via increasing the numbers of anaerobic microorganisms such as 0 . formigenes.

Probiotic yogurt might have a positive effect on this balance via increasing the numbers of anaerobic microorganisms including 0 . formigenes. Recently, Zarrati et al. [30] examined the effects of yogurt on fat distribution and the gene expression of proinflammatory factors in peripheral blood mononuclear cells in overweight and obese individuals. They suggested that probiotic yogurt had synergistic effects on T-cell subset-specific gene expression in mononuclear cells, on the percentage of fat and on body weight in overweight and obese subjects. Since HD patients have low-grade chronic inflammation with high cytokine levels, consumption of probiotics including yogurt and buttermilk might also be beneficial in this regard, although these patients should be wary of any development of hypercalcemia.

In recent years, the importance of the colo-renal axis in the progression of CKD has been underlined $[3,31,32]$. We also suggest that the relation between colon and kidney may influence cardiovascular outcomes in this population. It has been well established that cASBP, cADBP and pulse pressure are different from corresponding peripheral pressures as a consequence of progressive changes in arterial stiffness and pressure wave reflections along the arterial tree in healthy subjects. There is also evidence indicating that cASBP and cADBP are subjected to greater changes than peripheral pressures, which makes them closely related to cardiovascular damage. Hence, central blood pressures may be of higher clinical importance than peripheral pressures [33]. In addition, there is mounting evidence suggesting that monitoring of cASBP and cADBP as well as their cardiovascular relevance gain importance in the CKD population [34]. In the present study, we preferred to use the Mobil-O-Graph blood pressure device, which has been validated to estimate central hemodynamic parameters via measuring brachial oscillometric blood pressure waves noninvasively [35]. In this regard, we determined the central blood pressures as well as the relation of these parameters with serum oxalic acid and other parameters. Serum oxalic acid levels were found to be positively associated with both cASBP and cADBP as well as with peripheral SBP and DBP. These results confirm the importance of the colo-reno-cardiac axis in this population.

Aortic stiffness, as measured by carotid, femoral and aortic PWV, has been shown to be an independent predictor of cardiovascular morbidity and mortality in HD patients [36]. Hence, we preferred to determine PWV of HD patients as a direct measure of aortic stiffness, central hemodynamic parameters and the relation between serum oxalic acid and these parameters in the present study. We demonstrated that serum oxalic acid, glucose and urea levels were found to be positively correlated with PWV. In addition, PWV was independently predicted by serum oxalic acid, glucose and triglyceride, implying that arterial stiffness might be partially mediated by oxalic acid in HD patients. These results confirmed that oxalic acid might be considered an important URM in the pathogenesis of worse cardiovascular outcomes in HD patients.

Previous studies have demonstrated that serum oxalic acid cannot be effectively removed via HD [37,38]. Moreover, Costello et al. [39] had monitored plasma oxalate levels and oxalate removal rates in HD patients for approximately 2.5 years. Interestingly, they showed that plasma oxalate levels rose despite increased oxalate removal in these patients. France et al. [38] had similar results, and they concluded that dialysis treatment might stimulate the formation of oxalate by removing the product inhibition of lactate dehydrogenase in this population. To date, besides renal transplantation, HD is the most preferred 
Gulhan et al.: The Relationship between Serum Oxalic Acid, Central Hemodynamic

renal replacement therapy to remove uremic toxins. Modulation of colonic microbiota by consuming pre- or probiotics or by targeting the adsorption of toxic end products of microbial fermentation by adsorbents containing spherical carbon particles, such as AST-120, might be wise in CKD patients.

An alternative way to reduce serum oxalic acid levels in CKD patients might be to use phosphate binders including sevelamer hydrochloride. Besides its intestinal phosphate binding activity, in vitro studies showed promising results regarding the absorptive activity of sevelamer in uremic retention molecules including indole and $p$-cresol [32]. However, these effects have not been confirmed in either experimental CKD models of mice [40] or clinical studies in HD patients [41]. In the present study, we excluded those patients using calcium and non-calcium-containing phosphate binders to avoid any possible absorptive effects of these drugs on serum oxalic acid levels.

The present study has some limitations. First, this was a cross-sectional analysis of HD patients focusing on the relationship between serum oxalic acid, central hemodynamic parameters and PWV. Second, the sample size was relatively small. Third, there might be intra- and interstool sample variability in the amount of $O$. formigenes measured by realtime PCR. This was not a prospective controlled study, thus we cannot deduct any causeand-effect relationships from our findings.

\section{Conclusions}

This is the first study that demonstrates the absence of fecal colonization by 0 . formigenes as well as a relation between serum oxalic acid and cASBP, CADBP and PWV in HD patients. Uremic retention molecules are implicated in the uremic syndrome. There are many missing pieces in the puzzle; however, in the light of the findings of this study, replacement of O. formigenes with probiotics such as natural products might decrease serum oxalic acid levels and improve cardiovascular outcomes in HD patients. Further clinical and experimental studies are needed to confirm our results.

\section{Acknowledgement}

This study was supported by the Scientific Investigation and Project Foundation of the Mengucek Gazi Training and Research Hospital of Erzincan University.

\section{Disclosure Statement}

None of the authors have any relationships with or financial interests in companies related to the findings of this work. None of the authors declare any conflicts of interest.

\section{References}

1 Collins AJ: Cardiovascular mortality in end-stage renal disease. Am J Med Sci 2003;325:163-167.

2 de Jager DJ, Grootendorst DC, Jager KJ, van Dijk PC, Tomas LM, Ansell D, et al: Cardiovascular and noncardiovascular mortality among patients starting dialysis. JAMA 2009;302:1782-1789.

3 Evenepoel P, Meijers BK, Bammens BR, Verbeke K: Uremic toxins originating from colonic microbial metabolism. Kidney Int Suppl 2009;114:S12-S19.

4 Meijers BK, Evenepoel P: The gut-kidney axis: indoxyl sulfate, $p$-cresyl sulfate and CKD progression. Nephrol Dial Transplant 2011;26:759-761. 
Gulhan et al.: The Relationship between Serum Oxalic Acid, Central Hemodynamic

5 Meijers B, Toussaint ND, Meyer T, Bammens B, Verbeke K, Vanrenterghem Y, et al: Reduction in proteinbound solutes unacceptable as marker of dialysis efficacy during alternate-night nocturnal hemodialysis. Am J Nephrol 2011;34:226-232.

6 Goldfarb DS, Modersitzki F, Asplin JR: A randomized, controlled trial of lactic acid bacteria for idiopathic hyperoxaluria. Clin J Am Soc Nephrol 2007;2:745-749.

7 Curhan GC: Epidemiology of stone disease. Urol Clin North Am 2007;34:287-293.

8 Kelly JP, Curhan GC, Cave DR, Anderson TE, Kaufman DW: Factors related to colonization with Oxalobacter formigenes in US adults. J Endourol 2011;25:673-679.

9 Ferraro PM, Taylor EN, Gambaro G, Curhan GC: Soda and other beverages and the risk of kidney stones. Clin J Am Soc Nephrol 2013;8:1389-1395.

10 Turkmen K, Erdur FM: The relationship between colonization of Oxalobacter formigenes serum oxalic acid and endothelial dysfunction in hemodialysis patients: from impaired colon to impaired endothelium. Med Hypotheses 2015;84:273-275.

11 Chitalia N, Ismail T, Tooth L, Boa F, Hampson G, Goldsmith D, et al: Impact of vitamin D supplementation on arterial vasomotion, stiffness and endothelial biomarkers in chronic kidney disease patients. PLoS One 2014;9:e91363.

12 Asmar R, Benetos A, Topouchian J, Laurent P, Pannier B, Brisac AM, et al: Assessment of arterial distensibility by automatic pulse wave velocity measurement. Validation and clinical application studies. Hypertension 1995;26:485-490.

13 Hida M, Aiba Y, Sawamura S, Suzuki N, Satoh T, Koga Y: Inhibition of the accumulation of uremic toxins in the blood and their precursors in the feces after oral administration of Lebenin, a lactic acid bacteria preparation, to uremic patients undergoing hemodialysis. Nephron 1996;74:349-355.

14 Yasuda G, Shibata K, Takizawa T, Ikeda Y, Tokita Y, Umemura S, et al: Prevalence of constipation in continuous ambulatory peritoneal dialysis patients and comparison with hemodialysis patients. Am J Kidney Dis 2002;39:1292-1299.

15 Kalantar-Zadeh K, Kopple JD, Deepak S, Block D, Block G: Food intake characteristics of hemodialysis patients as obtained by food frequency questionnaire. J Ren Nutr 2002;12:17-31.

16 Wu MJ, Chang CS, Cheng $\mathrm{CH}$, Chen $\mathrm{CH}$, Lee WC, Hsu YH, et al: Colonic transit time in long-term dialysis patients. Am J Kidney Dis 2004;44:322-327.

17 Bammens B, Verbeke K, Vanrenterghem Y, Evenepoel P: Evidence for impaired assimilation of protein in chronic renal failure. Kidney Int 2003;64:2196-2203.

18 Hatch M, Cornelius J, Allison M, Sidhu H, Peck A, Freel RW: Oxalobacter sp reduces urinary oxalate excretion by promoting enteric oxalate secretion. Kidney Int 2006;69:691-698.

19 Jiang Z, Asplin JR, Evan AP, Rajendran VM, Velazquez H, Nottoli TP, et al: Calcium oxalate urolithiasis in mice lacking anion transporter Slc26a6. Nat Genet 2006;38:474-478.

20 Hatch M, Gjymishka A, Salido EC, Allison MJ, Freel RW: Enteric oxalate elimination is induced and oxalate is normalized in a mouse model of primary hyperoxaluria following intestinal colonization with Oxalobacter. Am J Physiol Gastrointest Liver Physiol 2011;300:G461-G469.

21 Hoppe B, Dittlich K, Fehrenbach H, Plum G, Beck BB: Reduction of plasma oxalate levels by oral application of Oxalobacter formigenes in 2 patients with infantile oxalosis. Am J Kidney Dis 2011;58:453-455.

22 Hatch M, Freel RW, Vaziri ND: Intestinal excretion of oxalate in chronic renal failure. J Am Soc Nephrol 1994;5:1339-1343.

23 Mogna L, Pane M, Nicola S, Raiteri E: Screening of different probiotic strains for their in vitro ability to metabolise oxalates: any prospective use in humans? J Clin Gastroenterol 2014;48(suppl 1):S91-S95.

24 Prokopovich S, Knight J, Assimos DG, Holmes RP: Variability of Oxalobacter formigenes and oxalate in stool samples. J Urol 2007;178:2186-2190.

25 Salminen S, Isolauri E, Salminen E: Clinical uses of probiotics for stabilizing the gut mucosal barrier: successful strains and future challenges. Antonie Van Leeuwenhoek 1996;70:347-358.

26 Otles S, Cagindi O, Akcicek E: Probiotics and health. Asian Pac J Cancer Prev 2003;4:369-372.

27 Nielsen B, Gurakan GC, Unlu G: Kefir: a multifaceted fermented dairy product. Probiotics Antimicrob Proteins 2014;6:123-135.

28 Garrote GL, Abraham AG, De Antoni GL: Chemical and microbiological characterisation of kefir grains. J Dairy Res 2001;68:639-652.

29 Marsh AJ, O'Sullivan O, Hill C, Ross RP, Cotter PD: Sequencing-based analysis of the bacterial and fungal composition of kefir grains and milks from multiple sources. PLoS One 2013;8:e69371.

30 Zarrati M, Salehi E, Nourijelyani K, Mofid V, Zadeh MJ, Najafi F, et al: Effects of probiotic yogurt on fat distribution and gene expression of proinflammatory factors in peripheral blood mononuclear cells in overweight and obese people with or without weight-loss diet. J Am Coll Nutr 2014;33:417-425.

31 Poesen R, Viaene L, Verbeke K, Claes K, Bammens B, Sprangers B, et al: Renal clearance and intestinal generation of $p$-cresyl sulfate and indoxyl sulfate in CKD. Clin J Am Soc Nephrol 2013;8:1508-1514.

32 Poesen R, Meijers B, Evenepoel P: The colon: an overlooked site for therapeutics in dialysis patients. Semin Dial 2013;26:323-332. 
33 Protogerou AD, Papaioannou TG, Blacher J, Papamichael CM, Lekakis JP, Safar ME: Central blood pressures: do we need them in the management of cardiovascular disease? Is it a feasible therapeutic target? J Hypertens 2007;25:265-272.

34 Weir MR, Townsend RR, Fink JC, Teal V, Anderson C, Appel L, et al: Hemodynamic correlates of proteinuria in chronic kidney disease. Clin J Am Soc Nephrol 2011;6:2403-2410.

35 Weiss W, Gohlisch C, Harsch-Gladisch C, Tolle M, Zidek W, van der Giet M: Oscillometric estimation of central blood pressure: validation of the Mobil-O-Graph in comparison with the SphygmoCor device. Blood Press Monit 2012;17:128-131.

36 Blacher J, Safar ME, Guerin AP, Pannier B, Marchais SJ, London GM: Aortic pulse wave velocity index and mortality in end-stage renal disease. Kidney Int 2003;63:1852-1860.

37 Mydlik M, Derzsiova K: Oxalic acid - important uremic toxin (in Slovak). Vnitr Lek 2010;56:695-701.

38 France NC, Holland PT, Wallace MR: Contribution of dialysis to endogenous oxalate production in patients with chronic renal failure. Clin Chem 1994;40:1544-1548.

39 Costello JF, Sadovnic MJ, Cottington EM: Plasma oxalate levels rise in hemodialysis patients despite increased oxalate removal. J Am Soc Nephrol 1991;1:1289-1298.

40 Phan O, Ivanovski O, Nguyen-Khoa T, Mothu N, Angulo J, Westenfeld R, et al: Sevelamer prevents uremiaenhanced atherosclerosis progression in apolipoprotein E-deficient mice. Circulation 2005;112:28752882.

41 Brandenburg VM, Schlieper G, Heussen N, Holzmann S, Busch B, Evenepoel P, et al: Serological cardiovascular and mortality risk predictors in dialysis patients receiving sevelamer: a prospective study. Nephrol Dial Transplant 2010;25:2672-2679. 